\title{
Hours, volume, and type of work of preregistration house officers
}

\author{
Peter J Leslie, John A Williams, Charles McKenna, Graeme Smith, Robert C Heading
}

Abstract
Objective-To determine the hours, volume, and type of work undertaken by preregistration house officers.

Design-Continuous observation of 472 hours of work performed by 12 preregistration house officers based in medical wards, using standard procedures for studying work patterns.

Setting-A teaching hospital with 340 beds assigned to general medicine and coronary care.

Subjects -12 Of the 16 preregistration house officers in medicine at the hospital.

Main outcome measures - The hours, volume, and type of work undertaken by preregistration house officers in February 1989, as recorded by trained observers on a one to one basis.

Results - The hours of duty ranged from 83 to 101 hours each week, the longest period of continuous duty being 58 hours. Each shift, house officers spent up to 25 minutes travelling between wards and an average of 85 minutes treating patients in wards that were cross covered. Between $50 \%$ and $71 \%$ of house officers' time was spent on patient oriented duties during the day; this fell to between $21 \%$ and $53 \%$ at night. Each doctor spent an average of $\mathbf{4 0}$ minutes filing when off duty after $6 \mathrm{pm}$.

Conclusions-Established procedures for studying workload were effective in monitoring doctors' hours, providing accurate information on the volume and type of work, which is essential to resolve the problems of medical staffing. The study showed that more house officers were needed and that the cross cover system should be stopped. As a result three extra preregistration house officers were appointed.

\section{Introduction}

Health authorities are in the process of implementing the changes initially outlined in the planning document Achieving a Balance to prevent house officers having to work rotas more onerous than one in three. ${ }^{\prime}$ Considerable attention has thus been focused on the hours worked by junior hospital doctors. ${ }^{2}$ One of the most favoured means of reducing the number of hours on call is a system of cross cover that requires doctors to be on call less often but to be responsible for more patients. Surprisingly, proposals for cross cover often take little account of the volume and type of workload already undertaken by junior doctors, and, although the cross cover systems may resolve the issue of "legal rotas," no information is available about the effects on care of having fewer doctors on call or the ability of these doctors to cope.

In February 1989 a dispute arose at the Royal Infirmary of Edinburgh when house officers in the medical wards were asked to increase their cross cover commitment. To help resolve the problem a study was commissioned to examine the volume and type of work being performed by house officers. It was hoped that the study would determine whether a reduction in rota requirements could be achieved merely by increasing the amount of cross cover or whether additional staff were required to cope with the workload.

\section{BACKGROUND}

The Royal Infirmary is Edinburgh's largest teaching hospital and has 280 medical beds plus an acute admission unit with 24 beds, a programmed investigation unit with 28 beds, and a coronary care unit with eight beds. Five medical units (10 wards) take responsibility for all emergency medical admissions in daily rotation. On average there are 21 (range 7-33) emergency admissions each day, and during the study the admitting unit had two house officers on call at night: a "first on," who stayed up all night and a "second on," who had the option of going to bed at midnight if work permitted. The four remaining non-admitting units (eight wards) were covered at night by three house officers.

At the time of the study 16 preregistration house officers worked a 1 in 2.8 rota, excluding prospective cover. Theoretically, doctors could have about two complete weekends off in five. A cross cover system, implemented in 1987 to eliminate all one in two rotas among resident staff, resulted in each house officer on call being responsible for between 65 and 110 patients in up to six different locations throughout the hospital.

In February 1989 an acute geriatric assessment unit with 20 beds was opened, replacing a long stay geriatric unit for which the house officers had been contracted to provide medical cover. One additional house officer post was allocated to the new unit, but to provide continuous cover out of hours the existing house officers in medicine were asked to include the new unit on two of every three nights. For each house officer this commitment would arise only once or twice a month, but the house officers thought that they were already overcommitted when on call and that adding a group of more acutely ill patients in another geographical location would seriously compromise their ability to provide acceptable care. This concern was endorsed by the consultant physicians. Although the house officers were performing duties in excess of a one in three rota, their hours of work and rates of pay were not an issue.

The concern of the medical staff was conveyed to the hospital's management. The house officers then requested that before any new arrangement was implemented a study should be performed to define their current workload.

\section{Subjects and methods}

The management of the Royal Infirmary commissioned Lothian Health Board's management efficiency unit to examine the hours of work, volume of work, range of duties, and location of duties undertaken by the house officers. The unit was invited to make recommendations, based on these observations, to improve the existing system. The protocol was developed and agreed by the unit's staff, the house officers, the junior medical staff representative, the consultant medical staff, the hospital management, and the BMA.

The study period consisted of 15 consecutive days and nights between 20 February and 6 March 1989, 22 sampled daytime periods (defined as 8 am to $6 \mathrm{pm}$ ), and 18 on call periods ( $6 \mathrm{pm}$ to $8 \mathrm{am}$ ). Although the house officers' contract stated that they were on duty from
Correspondence to:

BrMed F 1990;300:1038-41 
9 am to $5 \mathrm{pm}$ and on call from $5 \mathrm{pm}$ to $9 \mathrm{am}$, there had been a longstanding recognition that they actually worked from 8 am to $6 \mathrm{pm}$, and they were paid accordingly. The study was designed to provide a sample of daytime and on call periods from all the medical units within the hospital. Twelve of the 16 house officers employed in the medical wards were studied. Seventeen types of activity were defined (box) and a trained observer was allocated to each house officer to identify the time spent on each activity and record this to the nearest minute in a diary. The management efficiency unit required 66 person days to observe 472 doctor hours. Analysing the results and preparing a report for the hospital's management took a further 40 person days.

The number of occupied beds in each ward during the study was obtained, and each ward's figures were compared with annual statistics to ensure the validity of the reference period.

\section{Results}

\section{HOURS OF WORK}

House officers were on duty for between 83 and 101 hours each week, depending on whether they were on duty at weekends. In addition, each house officer spent an average of $7 \cdot 3$ hours of each week's off duty time completing various activities. In any rota the longest continuous period of duty was 58 hours (Saturday 8 am to Monday $6 \mathrm{pm}$ ) and the longest observed continuous period of work 60.5 hours. During the study none of the doctors was absent owing to holiday or sickness. It was estimated that if one of the house officers was absent for a week an extra 20 hours would be added to the weekly workload of the two remaining house officers in the unit affected.

\section{VOLUME OF WORK}

Data on the volume of work showed that a house officer in an admitting unit working a day on duty, the night first on call, and the following day on duty to

Mean proportion (percentage) of time that house officers spent on various activities while on call ${ }^{\star}$

\begin{tabular}{|c|c|c|c|c|c|c|c|c|}
\hline & \multicolumn{4}{|c|}{ Admitting unit } & \multicolumn{4}{|c|}{ Non-admitting unit } \\
\hline & \multicolumn{2}{|c|}{ Monday to Friday } & \multicolumn{2}{|c|}{ Weekend } & \multicolumn{2}{|c|}{ Monday to Friday } & \multicolumn{2}{|c|}{ Weekend } \\
\hline & $\begin{array}{l}8 \mathrm{am} \\
\text { to } 6 \mathrm{pm} \\
(\mathrm{n}=8)\end{array}$ & $\begin{array}{c}6 \mathrm{pm} \\
\text { to } 8 \mathrm{am} \dagger \\
(\mathrm{n}=8)\end{array}$ & $\begin{array}{l}8 \mathrm{am} \\
\text { to } 6 \mathrm{pm} \\
(\mathrm{n}=2)\end{array}$ & $\begin{array}{c}6 \mathrm{pm} \\
\text { to } 8 \mathrm{am} \dagger \\
(\mathrm{n}=2)\end{array}$ & $\begin{array}{l}8 \mathrm{am} \\
\text { to } 6 \mathrm{pm} \\
(\mathrm{n}=9)\end{array}$ & $\begin{array}{l}6 \mathrm{pm} \\
\text { to } 8 \mathrm{am} \\
(\mathrm{n}=6)\end{array}$ & $\begin{array}{l}8 \mathrm{am} \\
\text { to } 6 \mathrm{pm} \\
(\mathrm{n}=3)\end{array}$ & $\begin{array}{c}6 \mathrm{pm} \\
\text { to } 8 \mathrm{am} \\
(\mathrm{n}=2)\end{array}$ \\
\hline Examining patients & 14 & 25 & 9 & 26 & 7 & 16 & 31 & 9 \\
\hline Writing up case notes & 16 & 15 & 12 & 19 & 11 & 10 & 9 & 5 \\
\hline Ward rounds & 8 & 1 & 27 & & 19 & & 23 & \\
\hline Liaison and discussion & 12 & 7 & 11 & 8 & 14 & 5 & 8 & 7 \\
\hline Subtotal & 50 & 48 & 59 & 53 & 51 & 31 & 71 & 21 \\
\hline Completing request forms & 5 & 2 & 1 & 2 & 3 & 2 & 2 & 3 \\
\hline Preparing to take blood samples & 1 & 1 & 3 & 1 & 1 & 1 & & 3 \\
\hline Taking blood samples & 6 & 2 & 11 & & 5 & 3 & & 3 \\
\hline Packing specimens & 1 & 1 & & & 2 & & & \\
\hline Examining reports on patients & 3 & 3 & 4 & 1 & 3 & 2 & 2 & 1 \\
\hline Filing information in case notes & 4 & 1 & 2 & & 3 & 2 & & \\
\hline Subtotal & 20 & 10 & 21 & 4 & 17 & 10 & 4 & 10 \\
\hline $\begin{array}{l}\text { Making and receiving telephone } \\
\text { calls }\end{array}$ & 5 & 3 & 4 & 1 & 3 & 1 & 7 & 2 \\
\hline Answering bleep & 2 & 1 & 1 & & 2 & 2 & 1 & 1 \\
\hline Subtotal & 7 & 4 & 5 & 1 & 5 & 3 & 8 & 3 \\
\hline Preparing to give injections & 2 & 2 & 1 & 2 & 2 & 3 & 3 & 2 \\
\hline Giving injections & 3 & 2 & & 2 & 5 & 4 & 4 & 1 \\
\hline Subtotal & 5 & 4 & 1 & 4 & 7 & 7 & 7 & 3 \\
\hline Travelling outside ward & 6 & 3 & 1 & 1 & 4 & 4 & 4 & 2 \\
\hline \multirow{2}{*}{$\begin{array}{l}\text { Meal breaks, etc } \\
\text { Time spent in residency but } \\
\text { available }\end{array}$} & 12 & 10 & 13 & 10 & 16 & 4 & 6 & 6 \\
\hline & & 21 & & 27 & & 41 & & 55 \\
\hline Subtotal & 18 & 34 & 14 & 38 & 20 & 49 & 10 & 63 \\
\hline
\end{tabular}

^Further details of each activity are given in the box.

† Mean values for both house officers (first and second on call) after $6 \mathrm{pm}$.
Activities of house officers recorded during study

Patient oriented duties

- Examining patients for clerking in and subsequent examinations

- Writing up case notes, including writing discharge letters, death certificates, and transfer letters

- Attending ward rounds conducted by senior medical staff

- Liaison and discussion with nursing, medical, and paramedical staff and with patients and relatives

Clinical investigations

- Completing request forms for all laboratory tests, radiography, and pathology examinations

- Preparing syringes, specimen bottles, and labels for blood samples (but not writing request forms)

- Taking blood and separating sample into different specimen bottles

- Packing specimen bottles and request forms for postage

- Examining reports on patients, including laboratory reports, radiographs, and data filed on computer

- Filing summary forms and laboratory reports in casenote folders

Communication

- Making and receiving telephone calls

- Answering bleep

Giving treatment

- Preparing and assembling syringes, pumps, and intravenous infusions

- Giving injections and marking up drug charts at patients' beds

\section{Travelling time}

- Travelling outside parent wards to the admission ward, boarded out patients, surgical wards, cross covered wards, radiography department, and laboratories with urgent requests

Time spent not working

- Ineffective time, including coffee and meal breaks

- Time spent in residency but available if required

6 pm would typically spend only $4 \cdot 6$ hours not working (see box) during this 34 hour period. In non-admitting units the volume of work of the house officers on call did not diminish appreciably until after midnight.

\section{LOCATION OF DUTIES}

Because of the cross cover system some of the house officers' duties were carried out away from the parent wards, resulting in an average of 25 minutes being spent travelling each shift. House officers walked up to $3 \mathrm{~km}$ outside their wards, including travel to and from the residency. The median time spent each night in a ward that was cross covered was 85 minutes (range 32 to 171 minutes). House officers commented that the amount of time spent with a patient tended to be greater in a ward that was cross covered than in their parent unit as they often had had no previous contact with the patient.

\section{RANGE OF DUTIES}

The table shows the proportion of time that house officers devoted to each of the various activities during a shift. The time required for completing request forms and for filing reports in case records was greater than that shown because many house officers performed these duties outside their observed hours, when ostensibly they were no longer on duty. The hours worked while off duty were, however, studied for one day, and this showed that each house officer spent an average of 40 minutes doing filing when off duty after $6 \mathrm{pm}$. None of the house officers took a half day off 
after a night on call or had time allocated to tuition or private study.

Although a small proportion of time was spent answering bleeps, the resulting disruption was not estimated. During the time spent in the residency house officers had to answer on average five bleeps, two of these calls requiring a visit to a ward and three being dealt with by telephone.

Calculating the total time spent on "patient oriented duties" showed that house officers spent $51-71 \%$ of daytime shifts and $20-50 \%$ of night-time shifts directly involved in managing patients. This compares with the $15-26 \%$ quoted in comparable studies performed recently in the United States.

\section{RECOMMENDATIONS}

The management efficiency unit was asked to provide a descriptive report of the work pattern of the house officers and also to make recommendations on reducing the hours and volume of house officers' work. The recommendations on reducing working hours concentrated on two separate issues: firstly, methods by which non-medical tasks might be performed by other staff and, secondly, recommendations to affect directly the number of hours worked. It was estimated that employing clerical staff for filing would save $9 \cdot 7$ hours/unit/week; employing phlebotomists seven hours/unit/week; and delegating to nursing staff the administration of intravenous injections 3.8 hours/ unit/week. Clearly, reducing house officers' duties in this way would have a small but none the less important effect on the total hours worked.

Several possibilities were put forward to reduce the number of hours worked by house officers without altering their duties. Introducing a shift system with two rather than three house officers on duty for each unit between 8 am and $6 \mathrm{pm}$, Monday to Friday, with the other house officers delivering out of hours cover on a rotational basis would reduce the total number of hours worked by each house officer. In effect, one third of the six month preregistration period would be spent on night duty. This hypothetical system produced a rota averaging 73.5 hours each week, but during holidays and sick leave only one house officer would be on duty during the day for about 60 patients. A second proposal was an increase in cross cover, but as the medical staff considered the existing system to be excessive this proposal was not considered further.

The possibility that other medical staff, such as senior house officers and registrars, should take on some of the house officers' duties was considered. Existing rotas for most of these staff, however, were already in excess of one in three with prospective cover and were the subject of a separate review. It was thought that this would not provide an early solution to the house officers' problems and that nothing would be gained by merely transferring the problems with manpower and volume of work from one category of staff to another. A further possible solution was to employ extra house officers.

ACTION

The report and its recommendations were considered independently by the medical specialty group (the consultant physicians plus a representative of junior staff), the house officers, BMA representatives, and the hospital's unit management team and were subsequently discussed by representatives of each group. All concerned agreed that the only acceptable solution was to increase the number of house officers to create one in three rotas (including the prospective cover requirement) while simultaneously reducing the number of patients under each house officer's care at night by eliminating the cross cover duties. To achieve an equitable distribution of house officers among the units three additional house officer posts were recommended, to be integrated with the 16 existing posts in medicine and the one in geriatric assessment, giving a total of 20 whole time equivalent posts. This arrangement was judged to carry an acceptable volume and pattern of out of hours work for each house officer, and the average working week was estimated to be 72 hours (range 56-88 hours, depending on weekend duties). A scheme to employ part time clerical staff was implemented on a trial basis in an attempt to reduce the clerical duties of the house officers.

\section{IMPLEMENTATION}

By the time the results of the study were made known, the intended action agreed, and postgraduate educational approval for the new posts obtained, house officers had already been appointed to the hospital's medical wards for the six months beginning August 1989. It was therefore decided that the new arrangements would be implemented from 1 February 1990. Consequently, there has been little experience of the new system. The new rotas, however, do achieve an average of 72 hours a week, and house officers can have a half day off after being first on call for the admitting unit and before a weekend on call. The house officers now have time to attend clinical meetings and also usually leave the hospital by $6 \mathrm{pm}$ when not on night duty. Cover for the geriatric assessment unit has been allocated to one medical unit, thus assisting the integration of geriatric medicine and general medical training for the four house officers in that unit. The house officers in the other units are responsible for only their own unit's patients, who may be located in the parent wards or the programmed investigation unit or "boarded" elsewhere. Our early experience suggests that job satisfaction is greater and care of patients is more consistent. House officers are now less anxious about their workload, which previously had put them under pressure to deal with medical emergencies in unfamiliar wards with excessive haste.

The annual cost of employing three additional preregistration house officers with 11 units of medical time ( $£ 51708$ ) has been offset by a saving of $£ 15096$ resulting from reducing the number of units paid to each house officer. This gives a net cost of implementing the recommendations of $£ 36612$ each year, including employers' costs.

Two units took part in a pilot study of employing clerical staff, and during a 10 hour week two clerical officers filed between 700 and 750 documents per unit per week; most junior medical staff were able to finish work at least one hour earlier. Senior medical and nursing staff commented that ward rounds ran more efficiently because all the information was properly filed. A report on this pilot scheme is currently being considered by the hospital's management.

\section{Discussion}

This study shows that with careful planning by all interested parties modern methods for studying workload can be applied to the diverse work of junior doctors. As the information was collected by independent observers and not self recorded allegations that workload was exaggerated are avoided. Few studies of the working hours of the medical profession have been undertaken in the United Kingdom, in contrast to the United States, where there is over 20 years' experience of this type of medical audit. ${ }^{34}$ Any observational study may alter the behaviour of the subjects being observed, but despite this we believe that information of this type is essential to planning manpower in the health service.

This study contributed to the planning of manpower in two ways. Firstly, at the purely local level it 
provided data that allowed medical staff to reach agreement quickly with hospital management on measures that might solve the longstanding problem of house officer staffing in our medical wards. It seems unlikely that this measure of agreement would have been attained so easily had the information from the study not been available.

Secondly, the findings have wider relevance, providing an account of the patterns of work of a group of preregistration house officers in a large teaching hospital. Although the findings cannot be directly extrapolated to other hospitals, they show that accurate knowledge of the volume and type of workload are necessary to resolve problems of medical staffing in the 1990s. Attempts to reduce junior doctors' hours of duty by introducing or increasing cross cover arrangements are feasible only if this does not result in an excessive workload. Consequently, quantifying workload is as important as calculating hours on duty when changes in rota arrangements are being considered.

Posts for preregistration house officers are intended to provide not only a clinical service for patients but also supervised training and experience for the doctors. Many of the clerical activities of preregistration house officers contribute little to their training, and in our view employing filing clerks is worth while.

Medical workload cannot be appraised solely on the basis of time. The adequacy of communication with patients, particularly in respect of informing, reassuring, and comforting them, is important not only to the patients themselves but also for doctors' job satisfaction. This aspect of clinical activity is not easily measured, but its importance must be appreciated when the results of studies of work are interpreted.

This study was designed and undertaken to help resolve a specific problem in our hospital; it was not conceived as an investigation to generate results with a broader relevance. Consequently, although we are satisfied that it met the local need, the protocol may not be wholly appropriate for similar studies elsewhere. Likewise, the appropriate solution of house officers' problems may vary according to local circumstances. Issues such as the quality of training for preregistration house officers and the need to balance the number of preregistration posts available locally and nationally with the annual number of medical graduates are obviously relevant. Nevertheless, similar studies are necessary if the working patterns and training of junior doctors are to be improved without decreasing the quality of care.

We acknowledge the contributions and commitment of many medical staff, managers at the Royal Infirmary, Lothian Health Board, and representatives of the BMA to the design and execution of the study. The opinions expressed in this paper are ours.

1 United Kingdom Health Departments, Joint Consultants Committee, and Chairmen of Regional Health Authorities. Hospital medical staffing: achievin a balance. London: DHSS, 1987.

2 Scotland A. The hours doctors work. Brf Hosp Med 1989;41:211-2.

3 Lurie N, Rank B, Parenti C, Wooley T, Snoke W. How do house officers spend their nights? A time study of internal medicine house staff on call. NEngl f Med 1989;320:1673-7.

4 Payson HE, Gaenslen EC, Stargardter FL. Time study of an internship in university medical service. $N$ Engl f Med 1961;264:439-43.

(Accepted 9 March 1990)

\title{
Screening for carcinoma of the prostate by digital rectal examination in a randomly selected population
}

\author{
Knud V Pedersen, Per Carlsson, Eberhard Varenhorst, Owe Löfman, Kenneth Berglund
}

Department of Urology, University Hospital, 58185 Linköping, Sweden Knud V Pedersen, MD, urological registrar

Centre for Medical Technology Assessment and Department of Social and Environmental Medicine, Linköping University, Linköping, Sweden

Per Carlsson, PHD, assistant director

Owe Löfman, MD, head of department

Kenneth Berglund, MS, assistant director

Department of Urology, County Hospital,

Norrköping, Sweden

Eberhard Varenhorst, MD, associate professor

Correspondence to:

Dr Pedersen.

BrMed f 1990;300:1041-4

\section{Abstract}

Objective-To study the acceptability, costs, psychosocial consequences, and organisation of screening for carcinoma of the prostate.

Design-A randomly selected population was personally invited for digital rectal examination by a urologist and a general practitioner. Further examinations were performed if induration was felt. Each man completed a questionnaire on his response to the examination.

Setting-General practices in the area of Norrköping.

Patients-1494 Men aged 50-69 randomly selected from a population of 9026 .

Main outcome measure-Prostates having a firm nodular consistency.

Results-Carcinoma of the prostate was suspected in 45 of 1163 patients examined; in 10 by the general practitioners, in $\mathbf{1 0}$ by the urologists, and in 25 by both. Forty four men had a fine needle aspiration biopsy, and carcinomas were found in $\mathbf{1 3}$ cases. Of these, one had been suspected by the general practitioner, four by urologists, and eight by both. The cost for each man was $£ 11.60$, and the cost for each case of carcinoma detected and treated by potentially curative methods was $£ 2477$. Of the 13 men with carcinoma, 10 underwent radical prostatectomy and one radiotherapy. One man had. advanced disease and was given endocrine treatment, another was not treated. Only 193 men felt distress during the initial examination. Of the 44 men who had an aspiration biopsy, 25 experienced anxiety.

Conclusions-Screening for carcinoma of the prostate by a urologist or a general practitioner using digital rectal examination is a cost effective method of early diagnosis. Whether such screening leads to prolonged survival, however, remains doubtful.

\section{Introduction}

Cancer of the prostate is an increasing health problem in many countries. In Sweden it accounts for $23 \%$ of all cancers among men and is thus the chief form of cancer and the commonest cause of death from cancer in men. ${ }^{12}$ It often presents at an advanced stage with extensive local invasion or metastases, ${ }^{3}$ although it can be cured if detected early while still confined to the prostate; at this stage it usually causes no symptoms. Attention must therefore be focused on early detection and treatment. An effective screening programme that detected potentially curable prostatic cancer could alter the natural course of the disease by reducing overall mortality. Some major evaluations of screening programmes have been reported, but none of the populations was randomly selected ${ }^{4-7}$ and the reports did not give information about the prevalence and stage of prostatic cancer in an unselected population. Similarly, recent studies assessing digital rectal examination and transrectal ultrasonography were done in men who sought advice on their own initiative, who may therefore have constituted a biased, preselected 